La problemática etno-identitaria en sociedades escribales extinguidas: Mesopotamia en el III milenio a.C. Cuestiones historiográficas y metodológicas

Cristina Di Bennardis

Anuario No 32 / ISSN 1853-8835 / 2020

http://anuariodehistoria.unr.edu.ar/ojs/index.php/Anuario/index

\title{
La problemática etno-identitaria en sociedades escribales extinguidas: Mesopotamia en el III milenio a.C. Cuestiones historiográficas y metodológicas $^{1}$
}

\section{The ethno-identity problem in the extinguished scribal societies: Mesopotamia in the III millennium BC. Historiographic and methodological issues}

\author{
CRISTINA DI BENNARDIS \\ Universidad Nacional de Rosario (Argentina)
}

RESUMEN

El objetivo de este trabajo es contribuir a esclarecer las bases metodológicas necesarias para estudiar los procesos etno-identitarios en la antigua Mesopotamia. Se desarrollarán posicionamientos teóricos y categorias que se entienden esenciales para esta tarea, tales como etnia y alteridades, entre otras. Para ello se realizará una reseña historiográfica, a partir de diversos autores y trazando un recorrido sobre sus trabajos, de conceptos clave en el ámbito de aplicabilidad histórica. Todo este análisis tenderá a un enfoque pluridisciplinar histórico-antropológico para comprender los procesos etnoidentitarios en las sociedades escribales extinguidas, del III milenio a.C. en el valle aluvional de la cuenca del Eufrates y el Tigris y sus zonas de contacto.

Palabras clave: procesos etno-identitarios; étnia; identidad; étnica; Mesopotamia; III milenio; teoría.

ABSTRACT

The aim of this work is to contribute to the elucidation of the methodological bases necessary to study ethno-identity processes in ancient Mesopotamia. We will develop theoretical positions and categories considered essential to this task, such as otherness and ethnic group, among others. To this end, we will present a historiographical review of key concepts, from various authors and following the trajectory of their work, in the field of historic applicability. The whole analysis will tend to a historic-anthropological pluri-disciplinary approach to understand ethno-identity processes in the extinguished

\footnotetext{
${ }^{1}$ El presente texto es una producción de Cristina Di Bennardis, inédita hasta ahora. Se agradece a Julieta Ferrari, su hija, y a Leticia Rovira por editarlo para su publicación en este Anuario.
} 
La problemática etno-identitaria en sociedades escribales extinguidas: Mesopotamia en el III milenio a.C. Cuestiones historiográficas y metodológicas

scribal societies, from the third millennium B.C., in the alluvial valley of the Euphrates and Tigris basin and their contact areas.

Keywords: ethnic-identity processes; ethnic group; ethnic identity; Mesopotamia; third millennium B.C.; theory.

"la historia de la gestación y desarrollo de las etnias a lo largo de milenios y centurias, ha sido la historia de las relaciones entre distintos grupos humanos, la historia de los contactos interétnicos. Esta historia jamás estuvo desligada de las relaciones de poder, de las relaciones de pertenencia/exclusión $y$ dominación/subordinación que se establecieron entre los hombres y que, interpretadas dialécticamente se expresaron tanto a nivel de las prácticas: surgimiento concreto de sociedades, naciones, civilizaciones, imperios coloniales, estados; como a nivel de las representaciones: las categorias clasificatorias que surgirán de las ideas que los grupos así constituidos tenían de sí mismos y de los demás”. (Tamagno, 1988: 52).

\section{Los problemas}

El presente trabajo tiene como objetivo contribuir a esclarecer las bases metodológicas necesarias para afrontar el estudio de los procesos etnoidentitarios en una sociedad escribal extinguida, por lo cual se pone el acento en los posicionamientos teóricos y el andamiaje categorial que se evalúan adecuados para ello.

Los términos etnia y etnicidad son vocablos de antigua data, que han sido puestos desde hace al menos dos décadas en el centro de intensos debates en el campo de los estudios sociales. El vocablo etnicidad, refiere a los atributos identificatorios de una etnia y es la traducción del neologismo inglés ethnicity, modernización, a su vez, de la forma adjetival ethnikos del griego ethnos (Emberling, 2002:4), voz que tiene el significado de "pueblo" (ancestros comunes reales o míticos, tradición, lengua). Los griegos lo utilizaron para designar a las sociedades que no habían alcanzado la organización de ciudad-estado, instalando una visión de la alteridad desde un sesgo político. Ambos términos, intermitentemente, han cobrado protagonismo en los estudios sociales, adquiriendo un carácter polisémico, según las interpretaciones dependientes de momentos históricos y "escuelas" que las produjeron, así como por la

\section{anuario.}


característica elusividad y diversidad 2 de los procesos a los que hacen referencia. Esto requiere una toma de posición que ponga al desnudo las herramientas de análisis a ser utilizadas, ya que en el campo intelectual se han expresado desde los enfoques más prejuiciados y acríticos en torno a la caracterización de las distintas poblaciones humanas y sus relaciones -cuya máxima expresión son las posiciones nazi-fascistas-, hasta los intentos, dentro del campo de la ética científica, de comprensión y respeto por las diferencias y su compromiso con la acción social. Por lo mismo también se hace necesario un recorrido historiográfico.

Para entrar en tema, la extensa cita del epígrafe, representa una excelente sintesis explicativa de la importancia de plantearse el estudio de los procesos étnicos en una sociedad extinguida como es la de Mesopotamia en el III milenio a.C., si se parte de la convicción de que los mismos no son en absoluto modernos, en tanto se refieren a los contactos entre diversas poblaciones discretas y sus consecuencias; vínculos de los que se tiene constancia desde las más remotas épocas prehistóricas y que, en condiciones particulares condujeron a la conformación, ampliación o extinción de identidades colectivas. Además, reafirmar la universalidad de tales procesos étnicos -en tanto el aislamiento fue la excepción y no la norma entre las sociedades humanas. También se debe poner de relieve la complejidad de los problemas que es necesario abordar para desentrañar esta dimensión de la realidad social, en particular su ligazón a las relaciones de poder, que condicionan el tipo de vínculo entre distintas poblaciones; así como el conjunto de representaciones que generan las identidades sociales y las alteridades puestas en juego. Más allá de esta complejidad, la recuperación de la etnicidad en sociedades extinguidas tiene, tantos aspectos comparables, cuanto amplias diferencias en relación a los de la actualidad. Esta cuestión requiere de ciertos resguardos metodológicos que es parte de lo que se propone tratar en este trabajo sobre la base de anteriores estudios focalizados en los períodos: Protodinástico II-III (ca.2750-2340 a.C.), Sargónida (ca. 2340-2200 a.C.), 'Neo-sumerio' (ca. 2150?2000 a.C. $)^{3}$-periodización ritmada por los estratos de fuentes dependientes de los registros estatales preservados. En ellos, a pesar de lo aleatorio de su

2 El término elusiveness fue acuñado por Bromley (1974: 32), para referirse a los aspectos psico-sociales o a la "coloratura" particular que le otorga la etnicidad a la cultura. A su vez, Hobsbawm (1993/94: 12) afirma "Esta falta de coherencia o incluso esta arbitrariedad del concepto 'etnicidad', crea problemas considerables para definir a la identidad étnica".

${ }^{3}$ Se sigue la cronología media, la de mayor aceptación entre los especialistas. No se entrará en detalles en relación a las discusiones en torno al tema cronología, ya que no afecta lo esencial de este planteo metodológico; pero sí se considera necesario consignar la enorme complejidad que el tema conlleva y la inseguridad del estado actual de la cuestión. Al respecto, ver, por ejemplo, Creyer, 1995; Liverani, 1995: 27-35; Gasche, Armstrong; Cole \& Gurzadyan 1998. 
La problemática etno-identitaria en sociedades escribales extinguidas: Mesopotamia en el III milenio a.C. Cuestiones historiográficas y metodológicas

conservación y descubrimiento, y de lo sesgado de su información ${ }^{4}$, es posible obtener indicios sobre la génesis y el desarrollo de procesos de interacción socioculturales y políticos entre distintos pueblos ${ }^{5}$. Estos, identificables en las tablillas descifradas, son recuperables también en ciertos casos, en los testimonios epigráficos y arqueológicos.

El carácter escribal de las sociedades que habitaron la antigua Mesopotamia, ha demostrado fehacientemente, a partir del desciframiento de sus lenguas ${ }^{6}$, la coexistencia de culturas y grupos lingüísticos diversos. En el Protodinástico IIIII los documentos están escritos en sumerio ${ }^{7}$; como bien ha señalado Mario Liverani (1995: 143-145), ello ha conducido a la simplificación de llamar sumeria a esta cultura, cuando en realidad la situación es más compleja y el análisis del léxico muestra la presencia de por las menos tres aportaciones: términos presumerios 8 , con probables conexiones con el área iraní, sumerios propiamente, y los términos semíticos ${ }^{9}$ prestados. Que dependamos de la escritura para este análisis, no es un indicador de que la situación se produjera en ese momento y más bien es probable que el multilingüismo fuera característico ya en los primeros momentos de la colonización de la llanura mesopotámica ${ }^{10}$.

\footnotetext{
${ }^{4}$ Se aceptan las importantes observaciones sobre la interpretación de los documentos escritos por parte de Civil 1980, por cuanto el autor no sólo señala los límites, sino que también apela a la capacidad interpretativa de la antropologia, bajo determinados resguardos metodológicos.

${ }^{5}$ He dedicado mi Tesis de Doctorado Construcción de identidades étnicas, cultura y poder politico en la Mesopotamia del III milenio A.C., Facultad de Humanidades y Artes, UNR, 2006 (inédita), a este desarrollo.

${ }^{6} \mathrm{El}$ desciframiento del babilonio y el asirio, considerados actualmente variantes del acadio, ya se había iniciado en 1802 y el sumerio ya se conocía en grandes líneas desde 1900. Los avatares de sus desciframientos son relatados por Kramer, 1963.

${ }^{7} \mathrm{El}$ sumerio es una lengua aglutinante, es decir que no cambia la raíz de sus palabras, con semejanzas con otras conocidas como el euskera, el turco, el georgiano, pero sin parentesco probado con ninguna lengua conocida. Ver: Thomsen, 1984.

${ }^{8}$ Landsberger (1944) planteó la existencia de una lengua substrato que denominó protoeufrática o proto-transtigrida.

9 El desciframiento y clasificación de las lenguas y/o dialectos semíticos en Mesopotamia se vio facilitado por la persistencia hasta nuestros días de lenguas semíticas como el hebreo o el árabe. Como ha señalado Saggs (2000:30) “(...) las principales lenguas semíticas habladas antes de Cristo se encuentran todas por primera vez en una región delimitada por el Éufrates al este y el norte de Siria al norte. No hay motivos para pensar que los antecedentes geográficos del acadio fueran diferentes. (...)" 10 Obviando el problema del origen de los sumerios, tema irresuelto hasta nuestros dias, parto de la premisa -compartida por la mayoria de los investigadores- de que los sumerios ingresaron a la Mesopotamia desde algún otro lugar (entre varios se han sugerido el valle del Indo, o Irán) y que las tablillas arcaicas de finales de Uruk IV (ca. 3500- 3200 a.C.) expresan la lengua sumeria. Serian también los sumerios los protagonistas de la primera urbanización madura, ya en el período Uruk. Esto no
} 
La pluralidad lingüística explica el corte temporal, ya que el III milenio a. C. es la época en que es posible reconocer al sumerio como lengua hablada, además de escrita, coexistiendo con otras lenguas, varias de ellas semitas, en particular la que denominamos acadio desde la unificación de la baja y media Mesopotamia durante el reinado de Sargón de Acad (ca. 2334-2279) cuando se entra en un franco proceso de bilingüismo, que acompañará y rebasará el III milenio; ya que sobre el filo del II milenio, con el colapso de la III Dinastía de Ur y la masividad de la instalación amorrea ${ }^{11}$, junto a la toma del poder político en gran parte del territorio, se extingue la forma parlante del sumerio, pero permanece como lengua culta y litúrgica. Si bien la lengua no necesariamente coincide con la etnia y por lo tanto puede no ser un diacrítico identitario ${ }^{12}$, sí lo es en la mayoría de los casos por su estrecha relación con la cultura y la transmisión de la misma; por lo cual en el presente trabajo se sigue el criterio de considerar a los grupos lingüísticos como unidades etnolingüísticas, aunque se debe ponderar en el proceso histórico, las coincidencias, desplazamientos, reemplazos y toda otra modificación que, relacionada con aspectos sociales relevantes, pueda dar cuenta, al mismo tiempo, de transformaciones identitarias.

El recorte temático necesariamente implica la larga duración, en tanto se pone el acento en las transformaciones detectables a lo largo de todo un milenio (el III a.C.), ya que, como ha enfatizado Susana Devalle en coincidencia con Tamagno:

excluye, como se dijo, la simultánea presencia de pobladores nativos y/o de otra proveniencia.

11 Tradicionalmente se ha identificado a los amorreos con los mar.tu, que sería la designación sumeria, (vocablo que significa "oeste") y pertenecerian al grupo lingüístico semita occidental, cuya procedencia coincidiria con lo propuesto por Saggs (2000) que se cita en la nota 8. Sin embargo, planteos más actuales refieren a la posibilidad de que el amorreo no sea, en realidad, una lengua semítico-occidental, diferente del acadio (reconocido como semítico oriental) sino una variante aldeana o arcaizante del acadio, posición que hace mayor hincapié en la convivencia previa, que en la 'entrada' o 'migración' de los amorreos, e incluso en el origen común de lo que hasta ahora venimos considerando dos poblaciones y lenguas diferenciadas: acadios y amorreos: Buccellati, 2008: 142 y referencias a obras anteriores. En sentido semejante, pero con variantes cf. Porter, 2012: 268. También la importante discusión sobre la identificación o no entre mar.tu y amorreos Verderame, 2013: 41-55.

$12 \mathrm{El}$ mantenimiento o no de la lengua está asociado, en general, a las situaciones de estigmatización social, donde, la persistencia de su uso podría dificultar la supervivencia del individuo o el grupo involucrado. Esto está claro para los antropólogos que trabajan en el ámbito americano, donde, en determinadas situaciones las poblaciones originarias han perdido su habla hasta llegar a extinguirse, como ha sucedido en ciertos grupos aborígenes del sur de Argentina. Actualmente, se está produciendo el fenómeno inverso, en el marco de reivindicaciones políticas: hay una exigencia del respeto de sus lenguas que ha conducido a instalar, en ciertos casos, la educación bilingüe. 
La problemática etno-identitaria en sociedades escribales extinguidas: Mesopotamia en el III milenio a.C. Cuestiones historiográficas y metodológicas

"No siendo la etnicidad un fenómeno ahistórico, es precisamente en la dimensión de la longue durée en donde se formulan, mantienen y cambian las identidades colectivas. Esta dimensión temporal más que con lo cronológico tiene que ver con su substancia en movimiento: los contenidos sociales dinámicos que proveen elementos tanto para la reproducción de las identidades vividas cotidianamente, como para la emergencia de nuevas variantes de identidades ya existentes" (Devalle, 1999:44).

A su vez, es claro que abordar el análisis de procesos étnicos de una cultura extinguida con escritura, no puede realizarse bajo las mismas premisas metodológicas que rigen el estudio etnográfico o los actuales problemas étnicos en estados nacionales o sociedades multiétnicas. Al respecto Kathreen Kamp y Norman Yoffe en un pequeño pero relevante trabajo dedicado al II milenio a.C., aunque generalizable a otras épocas, ponen de relieve las posibilidades heurísticas de esta tarea al afirmar:

"Nuestro análisis de los datos mesopotámicos y de las varias teorias que han sido utilizadas para explicarlos, intentará ilustrar los problemas de interpretación más que pretender presentar exhaustivamente un conjunto de datos o de resolver algún problema histórico de integración sociocultural particular. No consideramos que las cuestiones de etnicidad en Mesopotamia sean menos ambiguas de lo que son en el Levante, ni consideramos los datos textuales como superiores a los datos no escritos. Toda clase de datos arqueológicos (incluyendo textos) es complementaria; ninguna ha de ser examinada como si las explicaciones de las interrelaciones entre los fenómenos socioculturales pudieran ser generados directamente por materiales que han sido recuperados en el presente. Más bien la tarea es hacer un modelo del comportamiento que produjo estos restos sobrevivientes en un patrón coherente para que los datos que no hayan sobrevivido puedan ser lógicamente deducidos. En tanto todas estas interpretaciones de sociedades extinguidas son fundamentalmente analogias con aquellas existentes o históricas, estos modelos deberán depender de comparaciones apropiadas con el presente histórico y sobre principios derivados de las ciencias de la organización social. Las hipótesis explicativas deberán ser, por lo tanto, construidas provechosamente como predicciones del pasado, que podrán ser verificadas (o falsadas) por la recuperación de nuevos datos o mejores (más inclusivos, económicos e internamente más consistentes) explicaciones.” (Kamp \& Yoffee, 1980:85-86).

Al centrar el problema de la interpretación en la ecuación pasado-presente los autores están marcando los ejes metodológicos sobre los que debieran asentarse los estudios sobre etnicidad en una sociedad extinguida: los estudios 
comparados; es decir apuestan a la posibilidad de recuperar las diferencias étnicas a partir del registro arqueológico, cotejado cuidadosamente con información etnológica y textual en sus contextos específicos. Además, en el penúltimo párrafo los autores acentúan la idea de que es el presente el que interroga (y "predice", al interpretarlo) al pasado.

De todos modos, en resguardo de la rigurosidad metodológica, es necesario conectar las distintas posiciones en relación al fenómeno de las identidades étnicas, con el conocimiento actual sobre las sociedades antiguas - la Mesopotamia del III milenio a.C. en particular- en un marco conceptual que apunta a reivindicar la especificidad de las sociedades antiguas, lo cual implica también fundamentar un uso cuidadoso de las analogías. Las analogías no pueden, obviar la imposibilidad de explorar las vivencias de los protagonistas de las identidades étnicas en una sociedad extinguida; la dependencia es total respecto de las fuentes textuales y arqueológicas; por tanto, el estudioso debe encontrar el medio de recuperarlas en las mismas, aunque sea parcialmente, y asumir que las fuentes están mediatizadas por el azar del hallazgo y la lente del investigador.

Estas limitaciones y diferencias remiten a dos aspectos metodológicos considerados claves para incorporar la problemática de la etnicidad en los estudios de las sociedades antiguas: enfoques que aporten adecuados criterios interpretativos; criterios de análisis de fuentes coherentes con lo anterior.

En relación a lo primero, surge de lo hasta ahora expresado que se adopta una mirada pluridisciplinar, con un natural anclaje en la antropologia y la historia. Adoptando esta perspectiva, es significativo, desde un punto de vista metodológico, el definitivo alejamiento de la perspectiva positivista que creía hacer ciencia por el sólo descubrimiento y relato fiel del documento, o por la descripción y clasificación de razas y especies; se trata de reconocer, apoyando el planteo de Kamp y Yoffee citado supra, que la ciencia social es una construcción que depende tanto de fuentes, datos y testimonios, ya sea de archivo o de trabajo de campo, cuanto de herramientas teóricas y conceptuales que permitan lecturas nuevas, más coherentes con la realidad que se ha tomado como universo de análisis.

Para ajustar este planteo, se debe partir, como se dijo, del reconocimiento de la especificidad de las sociedades antiguas. Las largas polémicas suscitadas entre los historiadores, sobre lo que se dio en llamar la dicotomía "modernidad versus primitivismo", quedaron prácticamente saldadas cuando desde distintos posicionamientos historiográficos -que tuvieron sus máximos representantes entre los historiadores marxistas y la "Escuela de Columbia"- se llegó a un consenso en cuanto a la necesidad de respetar esa especificidad, aunque la 
La problemática etno-identitaria en sociedades escribales extinguidas: Mesopotamia en el III milenio a.C. Cuestiones historiográficas y metodológicas

misma fuera analizada por unos y otros de modo variable ${ }^{13}$. Alentados desde distintas posiciones teóricas, investigadores de la talla de Igor Diakonoff $14 \mathrm{de}$ un lado, o Leo Oppenheim 15 del otro, coincidieron en que las relaciones económicas, sociales, políticas y las ideologías o el mundo simbólico poseen en estas sociedades una urdimbre que sólo es posible separar a efectos analíticos, pero que se expresan en concreto en un rol importante de las relaciones de parentesco en todas las dimensiones sociales; diferentes formas de acceso a la tierra que ignoran el concepto de propiedad privada moderno; relaciones sociales en las cuales el concepto de clase con sus connotaciones económicas aparece velado por condicionamientos como la dependencia o no de sectores palatinos; convivencia de organizaciones políticas diversas como tribus, comunidades rurales y estados; legitimidad politica vinculada al mundo divino y a las genealogias; omnipresencia de la religiosidad.

Esta postura implica una intensa conciencia de la necesidad de evitar el anacronismo, pero también un reconocimiento de las posibilidades heurísticas de las ciencias sociales en su indagación del pasado, que admiten un uso prudente pero fértil del método comparativo, no sólo en sentido espacial sino temporal 16. El planteo se basa en el reconocimiento de que existen matrices de experiencias sobre las que se han desarrollado las historias humanas unidas por las opciones y limites que provee la pertenencia a una única especie: Homo sapiens, raíz compartida que tiende el puente de la comprensión analítica de las sociedades humanas universalmente $\mathrm{y}$ hace posible partir de las experiencias actuales para intentar atisbar las experiencias del pasado. En palabras de Miguel Civil, refiriéndose a la posibilidad de nuestra comprensión de un himno real, en este caso el Himno $B$ a Shulgi, aunque también de sus limites:

"Sin embargo, es evidente que más allá de la ambición del poéta" nosotros no compartimos más que muy imperfectamente parte de su mundo, como lo saben bien aquellos que han tratado de traducir este dificil himno. Compartimos con el autor antiguo su condición humana. Alli reside para

\footnotetext{
13 Se citan de entre los numerosos trabajos que se podrian enumerar, dos obras de sintesis que se hallan en español. Desde el "materialismo histórico": Annequin, 1979 y Polanyi 1976 que trabajó desde una posición que Maurice Godelier (1976), denomina críticamente, en la misma Introducción de la obra, "sustantivista".

14 Se cita una de las obras más difundidas de las de este eminente maestro: Diakonoff, 1982 y un clásico: Diakonoff, 1975.

15 La obra más reconocida de Oppenheim 1964.

16 Importantes referencias metodológicas a los ritmos temporales y a las posibilidades del método comparativo en los trabajos compilados por Knapp, 1987.

17 Civil se refiere a los versos del poema que plantean que la reputación de Shulgi "pasará de mano en mano a las generaciones por venir".
} 


\section{CRISTINA DI BENNARDIS}

nosotros la esperanza de comprender su mensaje, pero también es donde se esconde el peligro del etnocentrismo ingenuo. " (Civil, 1978 : 227)

Así planteado el problema es notorio que el mismo involucra no sólo a la antropología y la historia, sino, como se dijo, al conjunto de las ciencias sociales $^{18}$. De hecho, la necesidad de actualizar la relación entre las teorias interpretativas de las ciencias sociales para llegar a una formulación más precisa del problema, surge de la evidencia de que las explicaciones de las relaciones entre distintos grupos humanos, en sus distintos tiempos y espacios, estuvieron connotadas por los recorridos disciplinares, en el contexto en que se produjeron sus desarrollos, situación a la que no escapan los estudios sobre las sociedades antiguas, entre ellas las del ámbito del valle del Éufrates y el Tigris. En cada caso, a su vez, varía la estructura metodológica de la cual se parte y la capacidad de hacerla consciente y explicitarla como exigencia de la tarea intelectual.

\section{Escudriñando la historiografia}

Desde esta perspectiva abarcadora, es necesario situar los estudios sobre Mesopotamia en el contexto general del conjunto de las ciencias sociales desde fines del siglo XIX, e ir descubriendo los nexos entre los distintos desarrollos disciplinares y la emergencia, las más de las veces velada, del tratamiento de los procesos etno-identitarios en el recorte espacio-temporal seleccionado.

Se observa, en primer lugar, el carácter prejuiciado de muchos de estos trabajos, en particular los escritos entre el último cuarto del siglo XIX y la 2da Guerra Mundial, ya que el concepto de etnia fue asimilado al de raza y los análisis se basaron en la premisa de la existencia de razas inferiores y superiores ${ }^{19}$, con el conflicto como vínculo casi inevitable, en el marco del profundo eurocentrismo que acompañó al desarrollo del neocolonialismo. El progreso había instalado su norma, basada en la superioridad material y "moral" de la "raza blanca" que justificaba las necesidades de expansión geográfica y sometimiento o aniquilación de otros pueblos, en aras de las "necesidades" de la civilización²0,

18 Eric Hobsbawm, refiriéndose a las tradiciones que dan sentido a identidades nacionales ha señalado que el estudio de la invención de la tradición es interdisciplinario. Es un campo de estudio que reúne historiadores, antropólogos sociales, y una variedad de otros trabajadores de las ciencias humanas, y no puede llevarse a cabo adecuadamente sin tal colaboración. Ver: Hobsbawm \& Ranger, 1983: 14.

19 La cabeza más visible de este planteo es De Gobineau, 1856.

20 La justificación de las relaciones de dominación coloniales encontró un campo propicio en las diferencias socio-económicas, políticas y culturales de los pueblos con 
La problemática etno-identitaria en sociedades escribales extinguidas: Mesopotamia en el III milenio a.C. Cuestiones historiográficas y metodológicas

en realidad las necesidades de materias primas y mercados del capitalismo en fase expansiva.

En ese contexto el ascenso del nacionalismo, estrechamente ligado al antisemitismo, y las terribles consecuencias a las que condujo, particularmente en su forma extrema, el nazi-fascismo, llevó, al término de la 2da Guerra Mundial, al abandono del término raza en las ciencias sociales, o a un uso muy cauto y preciso, limitado al reconocimiento de poblaciones con prevalencia de ciertos rasgos fenotípicos, que se considera no afectan la unidad psíquica del género humano ${ }^{21}$, y a evitar el uso del concepto de etnia por su contaminación con el anterior.

En el mismo marco histórico, las diferencias étnicas también habían sido entendidas como la distancia entre la "civilización" y otras formas de organización social, en particular las sociedades tribales, asociadas, o al nomadismo como estadio evolutivo, siguiendo los planteos del evolucionismo social22; o contraponiendo la organización tribal a la nación ${ }^{23}$. La caracterización de tribu resultó de la generalización de ciertas experiencias coloniales con tribus africanas y en especial con los beduinos camelleros y los pueblos árabes ${ }^{24}$.

Estos planteos se mantuvieron en el marco del eurocentrismo y un uso discrecional del evolucionismo, mucho más allá de la finalización de la 2da

los que se tomó contacto y a los que no sólo se consideró como salvajes o bárbaros, sino que se construyó un estereotipo imaginario de raigambre histórica. Así lo analiza Hurbon, 1993; a su vez que, Bestard \& Contreras, 1987, consideran el impacto de la conquista de América, en la comprensión del mundo de los europeos, a la luz de la herencia greco-latina y su concepción de los "bárbaros", o la experiencia de la "amenaza mongola" a Occidente. En épocas casi recientes todavía se observa este fenómeno, ver: Trinchero, 2000. Desde la perspectiva de las modificaciones que introdujo en Europa la conquista de América: Barzun, 2001.

${ }^{21}$ Ver la compilación de diferentes ensayos en: VV.AA., (1960) Le racisme devant la science. De todos modos, lo que se afirma no es lo mismo que decir que ha desaparecido el problema político del racismo y la discriminación, como es de comprensión evidente con la mera lectura de los periódicos, y que ha analizado con gran cuidado Foucault (1992) en su obra Genealogía del Racismo. De la guerra de razas al racismo de Estado. $22 \mathrm{El}$ evolucionismo social, particularmente en la versión de Lewis Morgan en Ancient Society de 1877, representó un legítimo intento de comprender la diversidad de desarrollos sociales, basándose en una comprensión darwiniana del ser humano, como parte de la evolución natural, contraria, por lo tanto, a los planteos creacionistas e idealistas, que son incluso perceptibles en la posterior teoría difusionista. Por tanto, no es razonable estigmatizarlo, sino ponderar sus usos.

${ }^{23}$ Connor, 1998, analiza esta cuestión en el punto de su obra "Tribalismo", pp. 105108.

24 Como ejemplos de la inmensa bibliografia etnográfica que impactó sobre los estudios sociales, se pueden citar: Charles, 1939; Coon, 1951; discusiones como las compiladas en Helm, 1968. 
Guerra Mundial. Fueron los usos del mismo, al auto-asignarse Europa el ser la cumbre de ese proceso -y no la propia teoría, al menos no en todas sus versiones, como lo ha señalado Vere Gordon Childe 25- lo que le dio una connotación de justificación del expansionismo colonial y del sojuzgamiento de otros pueblos.

Muchos de los estudios sobre Mesopotamia fueron teñidos por esas ideas. Así, en 1937 Wolfran von Soden ${ }^{26}$ atribuía el ascenso de los asirios a la mezcla de sangre hurrita -considerada aria- con la "raza semita". Solamente por medio del agregado de una raza superior podría la raza semita inferior haber logrado el desarrollo de un imperio. A su vez, E. A. Speiser (1932: 30) sugirió que la relación filológica es por lo general fuertemente indicativa de afinidades raciales 27. La difusión de la Antropología física y la antropometría, fue el correlato concreto a la noción de raza. Así, por ejemplo, S. Langdon en 1924 y H. Field en 1933, clasificaron cráneos del cementerio del Dinástico Temprano III en Kish como semitas (dolicocéfalos, o cabezas alargadas) o sumerios (braquicéfalos, o cabezas redondeadas). Se indagó incluso en las características físicas representadas en el arte para identificar razas. E. Meyer en 1906 fue quizás el primero en categorizar el arte en sumerio y semita de acuerdo a las características físicas representadas. Moortgat (1969) extendió además esta distinción a una arquitectura sumeria y semita. De este modo, el material fósil, las representaciones de distintos tipos humanos, y la distribución de las lenguas podrían todas indicar la localización de estas diferentes razas, cuyos movimientos y migraciones conducian a conflictos "raciales" entre ellas.

Sin embargo, a pesar de la fuerza de las convicciones prejuiciadas prevalecientes en el momento -que tornan desechables gran parte de estos trabajos-, algunos eruditos se opusieron desde un primer momento a estas asociaciones. Así, en 1936 Arthur Ungnad, a pesar de atribuir diferentes valores morales a cada raza, reconoció, que raza y lengua no coincidian, al menos en

25 Childe en su trabajo La evolución social (1973 [1ra. ed. inglés 1950]), en p. 10, comenta la teoría desarrollada por Darwin 1859 en su Origin of species, y señala que "(...) en la geología estratigráfica "después" significa "más arriba que", en una serie continua de depósitos sedimentarios. Así, en la evolución orgánica, los términos "superior" e "inferior" adquirieron significado objetivo y se liberaron de su subjetividad antropocéntrica. El Homo sapiens ha llegado a ser el mamífero superior no sólo por su conciencia de ello, sino por ser la última especie en aparecer". Childe intentaba de ese modo romper con el esquema prejuiciado de inferioridad-superioridad de las culturas; se diferencia, en ese sentido, de Tylor 1871; no sólo basa su análisis en "instituciones", sino que les asigna un rol prefigurador en la historia posterior.

26 Von Soden, 1937, en tanto actualmente se piensa en la posibilidad de considerar el hurrita como una lengua caucásica (Diakonoff \& Starostin, 1986).

27 Más tarde, Speiser (1950-51: 343) reconoció que "existe una marcada discrepancia entre la evidencia de los cementerios descubiertos en Sumer y la apariencia de los sumerios históricos representados en los monumentos". 
La problemática etno-identitaria en sociedades escribales extinguidas: Mesopotamia en el III milenio a.C. Cuestiones historiográficas y metodológicas

períodos históricos. Pero particularmente influyente fue la actitud de Thorkild Jacobsen (1939), quien en su artículo "The Assumed Conflict Between Sumerians and Semites in Early Mesopotamian History"28 publicado en los albores de la 2da. Guerra Mundial, se opuso enfáticamente a la identificación de conflictos raciales en Mesopotamia; demostrando, por el contrario, una amplia convivencia, a través del análisis de inscripciones, fuentes literarias, usos de nombres personales y selección de dioses sumerios para legitimar el accionar de los reyes acadios. Su excelente trabajo instala fuertemente la idea de que las luchas entre ciudades son luchas por la hegemonia, y postula, a través del análisis de fuentes textuales, que incluso la unificación de Mesopotamia bajo el "semita" Sargón de Acad, era reflejado positivamente en la literatura sumeria posterior, evidenciando la inexistencia de un conflicto racial. Reconociendo sin titubeos el valor politico del planteo de Jacobsen, es necesario observar que el autor prácticamente identificaba los conceptos de raza y etnia, lo que invalida, a la luz de los actuales estudios sobre etnicidad, su cerrada oposición a estos análisis.

Debido a las perversas consecuencias del planteo hitleriano acerca de la superioridad de la raza aria, y al peso de la autoridad académica de Jacobsen, se generó a partir de entonces, una predisposición contraria a los estudios étnicos en Mesopotamia. En consecuencia, pasa a segundo plano el tema de las peculiaridades de la relación sumero-acadia que -como es perceptible en la bibliografia posterior- es retomada luego desde otras perspectivas y con muchos resguardos.

A su vez, los vínculos entre acadios y amorreos, casi sin excepción, fueron abordados como relaciones dicotómicas entre pueblos nómades y sedentarios (y sus variantes de seminómades, semisedentarios, pastores, etc.), asociados a la interpretación de la relación tribus-estado. Ya se ha comentado supra que la caracterización de tribu resultó de la generalización de ciertas experiencias coloniales con tribus africanas y beduinos camelleros sobre todo árabes. Esto último reafirmó la idea del carácter naturalmente semita de los nómades, prejuicio que además tenía antiguo sustento en las versiones bíblicas de la historia del pueblo hebreo (e.g. Malamat, 1967). Una visión presente en la mayoría de los estudiosos hasta hace no tanto tiempo ${ }^{29}$, la señaló J.T. Luke de modo expresivo:

28 Jacobsen mantuvo su posición, aunque con aclaraciones, precisando su uso del concepto de raza y etnia y además en un trabajo de 1978-1979 responde a las objeciones de Gelb (1960).

29 Desde viejos trabajos como el de Peters, 1919; a tradicionales como el de Moscati, 1959. 
“(...) En la historia del cercano Oriente, el beduino árabe se convirtió en la fuente principal de la evolución étnica y cultural semítica, al igual que el idioma árabe fue lo básico para la comparación lingüistica. Los beduinos eran semitas, vivian en el desierto, organizados tribalmente y carecian de todas las marcas de "civilización superior". Por tanto, parecian representar perfectamente la etapa "primitiva" u original de la evolución semítica. La vida beduina era vista como un fósil, mostrando en el presente el carácter de todos los antiguos semitas (...)"(Luke, 1965:1)

Las posiciones que entrelazaban el vínculo entre semita, nómade y organización tribal, se afianzaron con las excavaciones iniciadas en la década del '30 por los franceses en Tel Hariri (Mari), en el Eufrates medio, y el extraordinario descubrimiento del archivo de la ciudad, con más de 20.000 tablillas correspondientes a tres generaciones de la primera mitad del siglo XVIII a.C. En ellas se mostraba un amplio espectro de relaciones entre los grupos tribales amorreos y estados urbanos, muchos de ellos con dinastias también amorreas. Una extensa lista de investigadores se dio a la tarea de transliterar, traducir y publicar las tablillas ${ }^{30}$, tarea todavía vigente. Sólo por dar una idea de la enorme repercusión de este archivo entre los asiriólogos, cabe mencionar a Charles, Dossin, Boyer, Birot, Kupper, Durand, Charpin, Ziegler, entre tantos otros investigadores, quienes dieron cuenta de temas tan variados como los textos administrativos, la correspondencia "diplomática", aspectos jurídicos; pero por sobre todo, como se dijo, desnudaron el aspecto multiforme de la relación entre los estados urbanos dirigidos por reyes amorreos, con las tribus del mismo origen aliadas a ellos o que los enfrentaban. A pesar de los fuertes indicios del dinamismo de las identidades étnicas, su constante metamorfosis al calor de los procesos políticos y la presencia de etnónimos en las fuentes, este riquísimo archivo ha sido apenas explotado desde esta perspectiva, de modo episódico y sin remitir al sostén teórico necesario para clarificarlo. Se omiten más precisiones ya que este tema ha sido tratado oportunamente por Jorge Silva Castillo y quien suscribe (Di Bennardis \& Silva Castillo, 2011; 2005).

\section{Los estudios modernos sobre etnicidad}

Como bien ha señalado Maxwell Owusu (1989), hasta la década '60-`70 antropólogos, sociólogos y lingüistas estaban más interesados en la lógica

${ }^{30}$ Publicadas, la mayor parte de ellas en las series ARM (Archives Royales de Mari) y ARMT (Archives Royales de Mari. Transcriptions et Traductions). 
La problemática etno-identitaria en sociedades escribales extinguidas: Mesopotamia en el III milenio a.C. Cuestiones historiográficas y metodológicas

interna de cada sociedad que en las relaciones entre sociedades y en la diacronía. Pero la historia no había cesado su movimiento y el fenómeno del denominado tercermundismo, el problema de la Revolución Cubana, la descolonización de África, la Guerra de Vietnam, estaban promoviendo actitudes críticas hacia las miradas occidentales sobre el resto del mundo.

Es en este período en que surge el enfoque moderno sobre el tema etnicidad. Por un lado, la antropología política (Hidalgo \& Tamagno, 1992:5), en la década del `60 comienza a cuestionar las miradas estáticas e internas del funcionalismo, el relativismo cultural y el estructuralismo -asumiendo que son todas escuelas de origen occidental ${ }^{31}$-, para propender a una nueva concepción de la etnicidad, considerada no un imperativo cultural sino una estrategia de lucha. Hay que recordar que las monografias etnográficas de las décadas del `40 y `50 solian crear limites artificiales entre los estados modernos y los pueblos sin organización estatal, englobados, a veces arbitrariamente, como ya se ha consignado, bajo la denominación de "tribus". Su reemplazo por los términos más neutros como etnia o etnicidad,

"conlleva un viraje disciplinar hacia lo no aislado en oposición a lo aislado, hacia lo contemporáneo versus lo primitivo, a lo universalmente aplicable versus lo no-occidental, hacia un enfoque tanto subjetivista como objetivista, hacia la idea de fluidez de los limites y de los contenidos en que se funda la identificación étnica" (Hidalgo \& Tamagno, 1992:3).

Coincidente con esta renovación, puede señalarse la influencia directa o indirecta que tuvieron algunas miradas críticas, sobre los estudios étnicos. Los trabajos de Edmund Leach, David Easton y Georges Balandier, son algunos ejemplos de entre los muchos investigadores que cuestionaron las prácticas y teorias antropológicas sustentadas hasta el momento y que el limite impuesto a este trabajo debe injustamente silenciar ${ }^{32}$. Leach (1977) desde un trabajo empírico, Sistemas politicos de la Alta Birmania, publicado en 1954, criticaba al funcionalismo y al evolucionismo simultáneamente, reinstalando una mirada histórica sobre los procesos sociales, por lo tanto, atendía también a los cambios y los conflictos, aportando así este matiz a la comprensión de los procesos interétnicos. Easton (1959:235) instala otra idea fructífera a la luz de los actuales conflictos étnicos: el concepto de arena politica, espacio en el que se dirimen el liderazgo y la competición y que permite pensar los procesos políticos

31 Un planteo ultra-crítico sobre estas escuelas se aprecia en el extenso manual Harris 1979.

32 Para solucionar, aunque más no sea en parte, esta injusticia, se mencionan dos compilaciones donde es posible contar con una exposición sistemática y abarcativa de esos aportes: Lewellen, 1985 y González Alcantud, 1998. 
más allá de la estatalidad. A su vez, en 1964 Georges Balandier 33 publicó su Antropología Política, con lo que daba el puntapié inicial al abordaje de lo político en la etnología francesa, con un racconto crítico de las posiciones hasta entonces, a las que asignaba gran ambigüedad, con usos terminológicos imprecisos: clientelismo, feudalismo (de uso y abuso en el mundo de los estudios antiguo-orientales ${ }^{34}$ ), e introduce el problema histórico de la consideración de las formas organizacionales pre-modernas que tendría más adelante una importante repercusión en el estudio de las sociedades antiguas, al incluirlas en la discusión sobre 'etnicidad, nación y estado'35.

Otro pilar de los estudios modernos sobre etnicidad fue el denominado giro Barthiano, es decir las propuestas rupturistas de Fredrik Barth en el Simposio realizado en la Universidad de Bergen en 1967 (Barth 1976). En él, Barth se opone a la tradicional mirada del etnógrafo y enfatiza la necesidad de considerar al grupo étnico como forma de organización social y remite, por tanto, al análisis del sistema de relaciones sociales, sus representaciones ideológicas, y los diacríticos identitarios que establecen las fronteras entre unos y otros grupos étnicos, fronteras más de una vez permeables, lo que no implica la desaparición de las diferencias. Este último enfoque tendrá un efecto positivo en los estudios sobre Mesopotamia antigua, aunque llegarán con una década de retraso.

Desde la década del '80, marcada por el fenómeno de la denominada "globalización", la posterior caída de la URSS en 1991 -y por tanto el surgimiento de un mundo de poder unipolar- no sorprende ver surgir posiciones que, por un lado, son una reacción contra las teorias generalizadoras y estructurales; y por otro, intentan considerar la autonomía del sujeto -tan empequeñecido y solitario en la aldea global- cuyas acciones son la fuente de creación de sentido, de significados, expresados en simbolos que los mediatizan. Este enfoque que se conoce como "interaccionismo simbólico"36, pone el acento en las relaciones intersubjetivas de construcción de las identidades individuales y sociales. Más allá de que esta posición implica subvertir las formas de análisis social, e incluso puede ser tachada de idealista, sus estudios han contribuido a comprender más profundamente el tema de las identidades individuales y colectivas en interacción, así como el poder de los símbolos en las sociedades humanas ${ }^{37}$.

\footnotetext{
33 En español en 1969. Un poco más adelante, en 1971 en el marco que se está reseñando le seguiria su Teoría de la descolonización.

${ }^{34}$ Ver el excelente planteo crítico de Claude Cahen (1979) sobre este problema, que no ha perdido actualidad.

35 Ver sobre estos tópicos: Anderson, 1993; Geller, 1991; 1993 y Goody 1985 y 1990.

36 Carlos Reynoso (1998:22-ss.) atribuye el surgimiento del "interaccionismo simbólico", a la reacción, especialmente en EE.UU. contra el establishment académico.

37 En ese sentido son importantes, entre otros, trabajos como el de Goffman, 1989 o Turner, 1967.
} 
La problemática etno-identitaria en sociedades escribales extinguidas: Mesopotamia en el III milenio a.C. Cuestiones historiográficas y metodológicas

De ahí en más, los nuevos problemas instalan el estudio de minorias étnicas, migraciones, pluralismo cultural, tendiéndose un puente con el campo de estudio de la sociología histórica, preocupada particularmente por la comprensión del fenómeno de nación, nacionalismo, extranjería y etnicidad, reverdecidos bajo el proceso de la denominada "globalización"38. El fin del siglo XX y el nacimiento del XXI aparece asi dividido entre dos pulsiones opuestas: respetar las diferencias en el marco de una sociedad multicultural, o extranjerizarlas, guetizarlas ${ }^{39}$. Esta última opción podría llegar a tener un carácter supranacional, como parecen indicarlo las últimas guerras e intervenciones de y en Afganistán, Irán, Iraq, Siria y sus consecuencias: migraciones y el problema de los refugiados, pareciendo querer instalar nuevamente lo que parecía una dicotomía superada: el enfrentamiento OrienteOccidente ${ }^{40}$.

\section{Miradas sobre la perspectiva etno-identitaria moderna en Mesopotamia}

Haciendo una apretada sintesis, se puede reconocer tres momentos significativos en cuanto a un tratamiento crítico que reinstala la problemática étnica, en Mesopotamia, luego de un largo silenciamiento del tema. El primero de estos momentos de sello crítico, es el reclamo de Ignace Gelb (1960) en su trabajo "Sumerians and Akkadians in their Ethno-linguistic Relations", presentado a la IXe Rencontre Assiriologique Internationale, oponiéndose al planteo de Jacobsen (1939) como ya se mencionó, propone la reconsideración del tema etnicidad, independizándolo de sus relaciones con el racismo y el nacionalismo. El autor atribuye singular importancia a la lengua, por lo cual denomina a las distintas poblaciones discretas, grupos etnolingüísticos. En sus propias palabras:

38 Entre los muchos trabajos y enfoques, se debe mencionar: Balibar \& Wallerstein, 1988 y respondiendo a la preocupación por los efectos de la presencia de los miembros de las ex colonias francesas en África; Pérez-Agote (1989), particularmente el punto 1.2 "Aspectos étnicos", con trabajos de J. Nagel, Connor y Ruiz Olabuénaga, sobre aspectos nacionales e internacionales de los movimientos étnicos modernos, su impacto sobre las democracias y el último citado sobre el fenómeno del País Vasco. Ver también el texto de Pujadas, 1993. Con sesgo americano la compilación de: Di Bennardis, Koldorf, Rovira \& Luciani, 2013.

39 Las posiciones son muy disímiles: Fraser, 1998 y 2000; Díaz-Polanco, 2000; Taylor, 1999; Bhabha, 2000 y 2002.

40 Edward Said, lamentablemente fallecido, alertaba hace ya tiempo sobre este problema en su obra Orientalismo (1990). Por el contrario, Samuel Huntington, bajo un pretendido análisis racional, adopta la más desnuda posición occidentocéntrica en su obra $E l$ choque de civilizaciones y la reconfiguración del orden mundial (1997). 
"Antes de entrar en una discusión del tema principal es necesario aclarar la terminología con respecto a mi uso del término 'etnolingüistico'. Hace algún tiempo ${ }^{41}$ definí los términos 'nación' (demos) y 'pueblo' (ethnos) de la siguiente manera: "La definición de "nación" es relativamente fácil: "nación" es un término político que denota un cuerpo de personas unidas por un estado o por una voluntad común a un estado. La definición del término étnico "pueblo" es más dificil, ya que los rasgos que caracterizan a un pueblo son más numerosos y más complejos. Los rasgos principales de un pueblo son la comunidad de tradiciones, costumbres, religión, cultura, idioma y posición geográfica. No todos estos rasgos tienen la misma fuerza $y$, de hecho, algunos de ellos pueden incluso estar ausentes. Muy influyentes son los lazos de tradición común con respecto a la descendencia. La posición geográfica compacta es un factor importante, aunque algunas partes de la misma unidad étnica pueden habitar en ocasiones áreas muy dispersas. La religión como lazo étnico varía en fuerza. El lenguaje como vehículo de la tradición es uno de los cimientos más sólidos de un pueblo. Como expresión exterior, el lenguaje se convierte en el símbolo con el que un pueblo se identifica más fácilmente. Para un pueblo, renunciar a su lengua en favor de otra normalmente significa la renuncia a su propia identidad étnica y la posterior asimilación a un grupo étnico del cual se toma el nuevo idioma (...)" (Gelb, 1960: 259).

Si bien este planteo no tendrá efectos inmediatos, será reconocido a posteriori y muestra en su plenitud los beneficios de la agudeza de un seguidor atento de los procesos sociales, en su campo de estudio y en el mundo del que era contemporáneo.

Un segundo momento crítico en relación a la problemática de los estudios étnicos en Mesopotamia antigua, se pone en evidencia a partir del reclamo de Kathryn Kamp y Norman Yoffee, en su trabajo publicado en 1980, ya citado más arriba. Esta posición se articula con el denominado "giro barthiano" en los estudios étnicos, ya reseñado. Al mismo tiempo Kamp y Yoffe hacen una apuesta a las posibilidades heurísticas de la etnoarqueología ${ }^{42}$, es decir a la facultad de recuperar las diferencias étnicas a partir del registro arqueológico. La etnoarqueología, forma parte de las transformaciones, consecuencia en principio

\footnotetext{
${ }^{41} \mathrm{El}$ autor se refiere a Gelb 1944.

${ }^{42}$ La tesis de Geoff Emberling (1995) Ethnicity and the State in Early Third Millenium Mesopotamia, representa el intento más acabado de aplicar este método.
}

\section{anuario.}


La problemática etno-identitaria en sociedades escribales extinguidas: Mesopotamia en el III milenio a.C. Cuestiones historiográficas y metodológicas

de los trabajos de la denominada "New Archaeology"43, la arqueología procesual. Esta participó de un modo u otro (tal vez sólo del "clima") de las posiciones renovadoras que cundieron desde la década del 50 , dirigiendo una mirada crítica, respecto de los métodos e interpretaciones de sus predecesores (Binford, $1962 ; 1965)$. Fue una escuela arqueológica con una actualizada propuesta de ligazón a la antropología y a las ciencias naturales y con un interés en deducir modelos generales de comportamiento y adaptación; poniendo énfasis en la comprensión de procesos diacrónicos en el marco de teorías sistémicas y de alcance medio. Más adelante se sumará, desde los '70, la denominada "arqueología post-procesual" (Hooder, 1988), con una idea de cultura como conjuntos heterogéneos de interpretaciones y representaciones superpuestas, e incluso opuestas (Emberling, 2016), rescatando al individuo y su mundo simbólico; perspectiva permeable, además, a las influencias del marxismo (Sprigg, 1984), el estructuralismo, los nuevos trabajos sobre el poder (Leone \& Shackel, 1987); e incluso las posiciones del feminismo (Engelstadt 1991).

El tercer momento crítico que se ha identificado corresponde al ciclo que encierra la realización de dos de los importantes eventos anuales para filólogos, arqueólogos, antropólogos, historiadores, dedicados al mundo antiguo-oriental: La 38e Rencontre Assyriologique Internationale realizada en París en 1991, abocada al tema La Circulation des Biens, des Personnes et des idées dans le Proche-Orient Ancien, y la que se llevara a cabo en Leiden en 2001 bajo el específico tema Ethnicity in Ancient Mesopotamia, que, como su nombre lo indica, reinstala la etnicidad como objeto de investigación en el ámbito de estos estudios, sorteando finalmente la interdicción de tres cuartos de siglo que pesara sobre ellos. Tal vez puede establecerse un ciclo madurativo de una década entre 1991 y 2001. Relacionado, por un lado, con el propio desarrollo de los estudios del área; por otro, por los planteos y revisiones críticas en cada una de las ciencias sociales y los acercamientos entre las mismas. Esto ha llevado a establecer nuevas delimitaciones; y las urgencias del presente que trasvasaron la anterior "interdicción" que desde el avance de la denominada globalización ha hecho estallar los moldes identitarios provistos por el estado-nación. Ello a su vez se visualiza en la emergencia de viejas identidades étnicas, la promoción del surgimiento de otras nuevas, o los conflictos que requieren innovadoras miradas sugeridas por los actuales problemas migratorios, procesos de diáspora y consecuente situación de refugiados, inmigrantes y minorias étnicas y nacionales. Todo esto ha estimulado estudios de procesos análogos en la antigüedad, aunque no siempre con las suficientes precauciones en torno al uso

43 Hooder, 1988, hace un buen análisis de este desarrollo disciplinar, a la vez que propone un enfoque más audazmente histórico y ofrece un repertorio bibliográfico representativo. También Renfrew \& Bahn, 2000. 


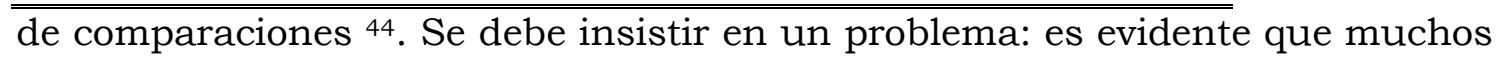
investigadores han incluido los términos etnia o identidad étnica, pero sin una apoyatura conceptual, lo que simplemente pareciera ser una forma 'políticamente correcta' de tratar los problemas de las relaciones entre grupos humanos diversos. En algunos casos es visible la superposición entre los términos 'lengua' y 'etnia' sin ninguna valoración crítica, aunque también deben consignarse aportes valiosos 45 .

\section{Enfoques, conceptos}

De la reseña historiográfica, surge la necesidad de tomar posición respecto de los conceptos operativos a utilizar. En términos generales se opta por un enfoque relacional y procesual, aunque reelaborado en base a la propia experiencia investigativa.

En primer término se apela a un concepto de etnia a pesar de la elusividad del mismo que ya se ha aclarado: una etnia es un conglomerado humano, de dimensiones diversas, con una especial y propia relación con un territorio determinado, sobre el que puede estar establecido de manera más o menos homogénea, compartiéndolo o no con otras etnias; que reconoce una historia común que les provee particularidades relativamente estables de lengua y cultura; y que posee autoconciencia de unidad y diferencia de otros conglomerados humanos -generalmente expresada en un etnónimo- base del sentimiento de pertenencia e identidad étnica, y que no necesariamente coincide con la pertenencia política. Se trata, en esta definición, apoyada en la formulada por Dragadze ${ }^{46}$ de destacar aspectos objetivos (territorio, lengua, cultura) y subjetivos (autoconciencia expresada en un etnónimo); también se pretende ponderar lo cuantificable y lo variable dentro de una etnia, al marcar la estabilidad de la lengua y ciertos elementos culturales, aunque señalando la relatividad de dicha estabilidad. Es de rigor subrayar que territorio y lengua no son requisitos indispensables, aunque sí frecuentes, en la identificación de una etnia.

A su vez, se considera a la identidad étnica, como forma particular de identidad. Se define como identidad al conjunto de factores subjetivos (la internalización de la cultura desde el momento mismo del nacimiento, conjunto de mediaciones interpersonales familiares y/o cercanas entre la constitución del sujeto y la

${ }^{44}$ Charpin, 1992, Durand 1992; Mander \& Pomponio, 2001; De Graef, 1999a y b; Lafont 1998.

45 Emberling, 2002; Mc Ineney, 2014; Rothman, 2015.

46 Citado por Renfrew 1990:177. 
La problemática etno-identitaria en sociedades escribales extinguidas: Mesopotamia en el III milenio a.C. Cuestiones historiográficas y metodológicas

cultura), así como los rasgos objetivos de esa misma cultura, construida socialmente, por un ámbito de pertenencia múltiple y aun contradictorio, pero que provee a individuos y grupos de un sentido de vida y que no excluye, ni los conflictos a nivel de autoidentificaciones coexistentes aunque dispares, ni la existencia de múltiples identidades, desde la individual hasta las macroidentidades étnicas y políticas, incluyendo sus representaciones ideológicas y simbólicas ${ }^{47}$.

Partiendo del concepto de etnia propuesto, se postula que la identidad étnica es la que selecciona a la etnia a la que se pertenece, como referencia y pertenencia y hay que comprenderla en su abigarrada dimensión social: como un complejo histórica y socialmente generado, vinculado a la estructura social y de poder, e imbricado en el ámbito de las representaciones simbólicas colectivas. Esta es una posición cercana a los denominados "constructivistas", en particular a aquéllos que reconocen el factor operador de la voluntad politica, pero en el marco del contexto socio-histórico que lo genera.

Se considera necesario hacer hincapié en el aspecto dinámico de la formación de las identidades étnicas y sus variaciones, y por tanto en la necesidad de analizar el proceso étnico: éste surge del reconocimiento de que la conformación de una etnia no es inmutable, no se sustenta en rasgos inmanentes a un determinado pueblo o cultura, sino que por su carácter histórico surge de un conjunto de procesos sociales, económicos, políticos, que generan, a su vez, diversas acciones de cohesión étnica que tienen su correlato en la autoconciencia. Estos procesos se desarrollan en un campo de interacción sumamente complejo, en el que la alteridad, la conciencia del otro, colabora en la propia autodefinición y es este juego relacional el que da lugar a la fluidez de las relaciones interétnicas. Éstas, abren posibilidades pacíficas, o de fricción o de exclusión/dominación, situaciones que se expresan en la conformación, fusión, modificación o desaparición de grupos étnicos, al calor de procesos más amplios, como la configuración de entidades políticas y estados.

Es importante señalar que las relaciones interétnicas no deben visualizarse exclusivamente desde la perspectiva del conflicto. La convivencia étnica y la permeabilidad de las fronteras étnicas son realidades constatables y es necesario evaluar las condiciones históricas concretas que las posibilitan en momentos precisos y que pueden ponerlas en riesgo en otras. Esta afirmación

\footnotetext{
47 Para analizar el fenómeno de la identidad fueron valiosos: Berger \& Luckmann, 1972; Levi-Strauss, 1981; Jacobson-Widding, 1983; Goffman, 1989; también los trabajos de Tamagno 1988; Rodríguez 1988 y otros investigadores argentinos reunidos en el mismo dossier "Identidad e identidad étnica"
} 
es estratégica desde un punto de vista de ética social, si se conecta la indagación del pasado con la comprensión del presente, como se ha subrayado.

Por último, no se considera un aporte tratar de delimitar las características socio-culturales o la sumatoria de rasgos -ya sean estos materiales, organizacionales o simbólicos- que otorgan identidad a cada etnia. En cambio, sí se entiende necesario que los estudios étnicos permanezcan atentos a la significación y acción del conjunto de factores (entre ellos el protagonismo del poder político) que actúan sobre la identidad étnica y las relaciones interétnicas. Es importante consignar que las identidades étnicas pueden convivir con otras identidades emergentes, e incluso impuestas (urbana, nacional, colonial, imperial), incluso quedar soterradas y reaparecer en circunstancias favorables o al calor de nuevos conflictos.

Para completar este esquema en torno a los problemas metodológicos, es necesario reconocer que la distancia temporal y el carácter de las fuentes, testimonio de sociedades extinguidas como las de la Mesopotamia antigua, representan un obstáculo de la mayor seriedad, que enturbia aún más la característica opacidad de las identidades étnicas. Sin embargo, se postula que, a pesar de las reservas del caso, es viable un acercamiento a las identidades étnicas desaparecidas por vía del uso de las fuentes textuales en sentido amplio, donde es posible reconocer la presencia de distintas etnias por sus etnónimos, al tiempo que las mismas permiten acceder al campo de las representaciones mentales donde se expresan aspectos de la identidad y la contrastación étnicas, como parte de un espectro más amplio de relaciones internas y externas de jerarquización, complementariedad, oposición y/o subordinación.

Para esto es necesario partir de una concepción del documento histórico que amplíe el horizonte de la interpretación. El explícito ideal de la historiografía documentalista ha sido abordar el texto como información sobre el pasado, con el objetivo de reconstruirlo con la mayor verosimilitud posible. Acompaña esta actitud una búsqueda de las condiciones intrínsecas que permitan distinguir el texto propiamente histórico, del texto literario. Pero la profunda renovación teórico-metodológica de las ciencias sociales en las últimas décadas, ha llevado a que, desde distintas perspectivas teóricas, lingüísticas, literarias, y también desde la historia, se haya revisado (y relativizado) la concepción puramente documentalista de la historiografia. Y se ha ido aún más lejos: se plantea la revalorización del documento como texto en sí, al margen de su clasificación (Bouvet 1989/90). Siguiendo a Michalowski (1984) se podría afirmar que el estudio de las fuentes textuales es parte de la problemática más amplia de la narrativa, “... en un tono radical, se podría muy bien postular que no existe tal cosa como historia o historias, sino que solo hay textos: antiguos o modernos" (Michalowski, 1984: 237). 
La problemática etno-identitaria en sociedades escribales extinguidas: Mesopotamia en el III milenio a.C. Cuestiones historiográficas y metodológicas

Es de destacar que el campo de los estudios orientales ha sido pionero, en gran medida, en el uso del texto literario; como señala William Hallo (1987) apostando a la validez del uso de las fuentes literarias -con las debidas precauciones- en reconstrucciones historiográficas “...En el caso de Israel, esta proposición es virtualmente axiomática..." (Hallo, 1987: 9). En tanto, Liverani, da un buen ejemplo de esta nueva postura cuando afirma, en relación a las cartas de E1 Amarna: “... el problema no es llegar a saber si un hecho narrativo es "verdadero", sino por qué ha sido asentado y por qué de ese modo particular y no de otro. En terminología lingüistica podemos decir que un análisis connotativo es más factible e interesante que uno denotativo" (Liverani, 1983: 42).

No hay duda que la reconstrucción del contexto de una sociedad extinguida siempre conlleva el riesgo de caer en el anacronismo, ya que el acceso al documento se hace desde una sociedad y una cultura (la nuestra) que ofrece sus propios códigos de valoración y clasificación de lo relatado y opera seleccionando líneas interpretativas y nuevas indagaciones (White, 1985; AsherGreve \& Asher 1998). Sociedad y cultura, son entendidas aquí como totalidades que proveen un sentido a la vida, filtran y jerarquizan las experiencias y hacia el interior están resignificadas por experiencias de grupos, clases, ámbito de pertenencia rural o urbano; o sea se deben tener en cuenta la multiplicidad vivencial y las elaboraciones simbólicas, en sentido individual y colectivo.

Además, para el caso de las antiguas sociedades escribales, se debe atender al hecho de que el registro escrito es casi exclusivamente producción de un sector: el estado o los grupos ligados al poder politico. Esto es así para cualquier clase de documentos, pero se manifiesta más crudamente en el caso de la literatura ya que ésta es la reelaboración realizada por una élite ilustrada del antiguo fondo cultural colectivo, siendo también la responsable de su acrecentamiento y modificación. Al mismo tiempo, el paradigma del origen estatal de la producción de las fuentes textuales, afirmación tanto más contundente cuanto más atrás se retrocede en el tiempo, ha conducido al sobredimensionamiento del rol del estado en estas sociedades y a la opacidad de las voces que no pertenezcan al sector de la élite. Sin embargo, los hombres y mujeres comunes dejaron señales -a veces apenas perceptibles-, indicios a los que sólo es posible encontrar si se parte de la premisa de su existencia. Encontramos esas premisas en la confluencia de las miradas de la antropologia y la historia social.

Los señalamientos anteriores indican los resguardos, pero también la audacia con que habrá que acercarse a las fuentes, esa materia prima parlante y al mismo tiempo muda por la intencionalidad con que informa, deforma y omite. Habrá que referirse a la contextualidad social extralinguistica para que las

\section{anuario.}


interrogaciones presentes puedan realmente interpelar al pasado, aun en aquellos aspectos que no se quiso, o no pareció importante a los escribas, o a sus mismos protagonistas, consignar, si se toma en cuenta la amplitud de la tradición oral, aún para acciones importantes como matrimonios y contratos (Goody 1985; 1990).

Para el caso de las obras literarias sumerias, la mayor parte de ellas se conocen por versiones datadas aproximadamente entre 2100 y 1650 a.C., por lo tanto, provienen prácticamente de fuera del período de uso de la lengua sumeria, e incluso de copias realizadas por hablantes semitas, acadios o amorreos, para quienes el sumerio había devenido en lengua culta y litúrgica. Sin embargo, no considerarlas, sería desconocer, por un lado, la trascendencia temporal de las obras literarias en relación al tiempo de su composición, como así también, que el hecho mismo de su supervivencia ofrece un indicio de la significación de los valores profundos que contienen. Por otra parte, la práctica de las escuelas de escribas de entrenar a sus discipulos, sobre la base del copiado infinitas veces de los textos seleccionados precisamente por ser considerados valiosos, relativizan el anacronismo de su utilización para épocas anteriores a las copias que han sido fechadas. Es entonces, un criterio metodológico consciente el utilizar, por ejemplo, el poema Epico de Gilgamesh -conocido en su versión más completa por la colección del rey asirio Ashurbanipal (668-631 a.C.) de su biblioteca en Nínive, copiada, a su vez de una versión del período Paleobabilónico, que a su vez se compusiera en base a historias, leyendas y fragmentos sumerios- para dar cuenta, de los valores identitarios atribuidos a la vida urbana por los sumerios, como bien lo ha señalado Hans Nissen (1988: 95 y 107).

Este enfoque permite valorar en toda su dimensión al concepto de etnopoesía acuñado por Jeda Jason $(1969 ; 1977,1979)$. Jason sostiene que la etnopoesía es, muchas veces, la expresión escrita de viejas tradiciones orales, lo que pone de relieve la continuidad y antigüedad del fondo cultural que la sustenta y corrobora lo planteado supra ${ }^{48}$. La autora señala que puede englobarse en esta denominación a todas aquellas manifestaciones literarias que expresan la cosmovisión de un pueblo y la relación del hombre con el mundo que lo rodea. De este modo, un mito, un poema, son tan válidos para reconstruir el pasado como la inscripción de una estela conmemorativa o una lista de ofrendas ${ }^{49}$.

Textos como Enmerkar y el señor de Aratta, o los correspondientes al género de

${ }^{48}$ La cuestión de la no existencia de una dicotomía entre sociedades letradas e iletradas ha sido claramente analizada por Jack Goody, 1985

49 De la misma forma que las fuentes de índole económica, administrativa, epistolar, inscripciones conmemorativas, etc., ya que todas son ineludibles para un estudio que se plantea desde un enfoque pluridisciplinar, como el propuesto. 
La problemática etno-identitaria en sociedades escribales extinguidas: Mesopotamia en el III milenio a.C. Cuestiones historiográficas y metodológicas

las lamentaciones (por la destrucción de Ur, de Sumer, de Agadé), el casamiento de Martu $^{50}$, entre tantas otras, pueden clasificarse dentro del rubro etnopoesía, en la medida que recogen vivencias, pautas culturales, conceptos de tiempo y espacio, tanto como valoraciones que involucran a grupos etnolingüíticos identificables, a la vez que expresan un "nosotros" y "los otros", donde se evidencian los efectos de las acciones políticas sobre la delimitación y la cualificación (mayor o menor permeabilidad) de las fronteras étnicas.

\section{Finalizando...}

En el recorrido realizado se ha intentado desplegar la armazón metodológica que se considera apropiada para rescatar la experiencia de los procesos étnicos en una sociedad escribal extinguida, en este caso Mesopotamia del III milenio a.C. y que podría sintetizarse del siguiente modo:

- Interrogaciones al pasado modeladas en las vivencias del presente, que habilitan un uso cuidadoso del método comparativo en sentido espacial y temporal.

- Enfoque pluridisciplinar, con especial anclaje en la antropología y la historia.

- Identificación de las posiciones historiográficas que condicionan las interpretaciones en el campo de estudio.

- Cuidadosa consideración del contexto (social, económico, político, cultural e ideológico-religioso), basado en la premisa de la especificidad de las sociedades antiguas, recuperada a través de una lectura renovada de las fuentes textuales y arqueológicas.

- Sustrato teórico-conceptual puesto a prueba durante la indagación.

50 Buenas versiones de estas fuentes pueden consultarse en la clásica compilación de Pritchard 1969. También en Kramer, 1963. Una versión más actualizada de "El casamiento de Martu" en Kramer, 1990. Es provechoso consultar las transliteraciones $\mathrm{y}$ traducciones de distintas fuentes que se encuentran en el Proyecto The Electronic Text Corpus of Sumerian Literature https://etcsl.orinst.ox.ac.uk/ creado por la Universidad de Oxford en 1997.

\section{anuario.}


- Corpus de fuentes en sentido amplio, equiparando las llamadas literarias e históricas.

A modo de conclusión preliminar, se evalúa como condición positiva el enfoque pluridisciplinar, con eje histórico-antropológico (sin desdeñar el aporte filológico, que no se cuestiona, sino que se aprovecha en sus aportes eruditos), para comprender los procesos etno-identitarios en las sociedades escribales extinguidas, que desplegaron sus desarrollos a lo largo del III milenio a.C. en el valle aluvional de la cuenca del Éufrates y el Tigris y sus zonas de contacto. Sus límites, a su vez, son los mismos que para un enfoque positivista: el universo de análisis está constituido sólo por los residuos de las sociedades que los protagonizaron. Entremedio, ya se plantee la interpretación como deducción lógica o como mera imaginación, cuantos más ojos estén poniendo a la sociedad bajo estudio en foco, más aristas y detalles de sus huellas serán descubiertos.

\section{Bibliografia}

Anderson, B., (1993 [1ra. ed. inglés 1983]) Comunidades imaginadas. Reflexiones sobre el origen y difusión del nacionalismo. México: FCE.

Annequin, J. et alii, (1979 [1ra. ed. francés 1975]) Formas de explotación del trabajo y relaciones sociales en la antigüedad clásica. Madrid: Akal.

Asher-Greve, J. \& Asher, A. L. (1998) "From Thales to Foucault...and back to Sumer", En Prosecky, J. (ed.) Intellectual Life of the Ancient Near East. Papers Presented at the 43rd Rencontre assyriologique internationale, Prague, July 1-5, 1996. Praga: Academy of Sciences of the Czech Republic, Oriental Institute, pp. 29-40.

Balandier, G. (1969 [1era ed. en francés 1967]) Antropología Politica. Barcelona: Península.

Balandier, G. (1973 [1ra. ed. francés 1971]) Teoría de la descolonización. Buenos Aires: Tiempo contemporáneo. 
La problemática etno-identitaria en sociedades escribales extinguidas: Mesopotamia en el III milenio a.C. Cuestiones historiográficas y metodológicas

Balibar, E. \& Wallerstein, I. (1988) Race, nation, clase. Les identités ambiguës. París: Éditions la Découberte.

Barth, F. (1976 [1era ed. en noruego 1969]) Los grupos étnicos y sus fronteras. México: FCE.

Barzun, J. (2002) Del amanecer a la decadencia, quinientos años de vida cultural en occidente (de 1500 a nuestros dias). Madrid: Taurus.

Berger, P. \& Luckmann, T. (1972 [1ra. ed. inglés 1966]) La construcción social de la realidad. Buenos Aires: Amorrortu.

Bestard, J. \& Contreras, J. (1987) Bárbaros, paganos, salvajes y primitivos. Una introducción a la Antropología. Barcelona: Barcanova.

Bhabha, H. K. (2000) La problemática de la diversidad cultural, documento UNESCO.

Bhabha, H. K. (2002 [1ra. ed. inglés 1994]) El lugar de la cultura. Buenos Aires: Manantial.

Binford, L. R. (1962) "Archaeology as Anthropology", American Antiquity 28 (2): 217-225

Binford, L. R. (1965) "Archaeological Systematics and the Study of Cultural Processes", American Antiquity 31 (2): 203-210.

Bouvet, N. (1989-1990) "El texto literario como documento histórico", Anuario Escuela de Historia 14, UNR: 73-84

Bromley, Y.V. (1974) “The Term 'Ethnos' and Its Definitions”, En Grigulevich, I.R. \& Koslov, S.Y. (Edits.) Races and Peoples. Contemporary Ethnic and Racial Problems. Moscú: Progress Publishers, pp.17-44.

Buccellati, G. (2008) "The Origin of the Tribe and of 'Industrial Agropastoralism in Syro-Mesopotamia", En Barnard H. \& Wendrich, W. (eds) The Archaeology of Mobility. Los Ángeles: Cotsen Advanced Seminar Series UCLA, pp. 141-159.

Cahen, C. (1979 [1ra. ed. francés 1963]). "Reflexiones sobre el uso del término 'feudalismo'" en VV.AA. El modo de producción feudal. Madrid: Akal, pp. 7-19.

Charles, H. (1939) Tribus moutonnières du Moyen Euphrates. Damasco: Institut Français de Damas. 


\section{CRISTINA DI BENNARDIS}

Charpin, D. (1992) "Immigrés, réfugiés et déportés en Babylonie sous Hammurabi et ses succsseurs", En Charpin, D. y Joannes, F. La circulation des biens, des personnes et des idées dans le Proche-Orient ancien. Actes de la XXXVIIIe Rencontre Assyriologique Internationales, Paris, 1991. Paris: Editions Recherche sur les Civilisations, pp. 207-220.

Childe, V. G. (1973 [1ra. ed. inglés 1950]) La evolución social. Madrid: Alianza.

Civil, M. (1980) "Les limites de l'information textuelle", En Barrelet, M. (ed.) L'archéologie de l'Iraq du début de l'époque Néolitique à 333 avant notre ère. Perspectives et limites de l'interprétation anthropologique des documents, actes du colloque international. París: Editions du Centre National de la Recherche Scientifique, pp. 225-232.

Connor, W. (1989) "Democracia, etnocracia, y el estado multinacional moderno: paradojas y tensiones", En Pérez-Agote, A. (Ed.) Sociología del Nacionalismo. Bilbao: Servicio Editorial Universidad del País Vasco, pp.111-130.

Connor, W. (1998) Etnonacionalismo. Madrid: Trama.

Coon, C. S. (1951) Caravan: The Story of the middle East. New York: Holt.

Creyer, F. H., (1995) "Chronology, Issues and Problems", en Sasson, J.M., Civilizations of the Ancient Near East. Vol. I. Londres: Charles Scribner's Sons, pp. 656-664.

Darwin, C. (1958 [1 era ed. en inglés 1859]) El origen de las especies. México: Grijalbo.

De Gobineau, J.A. (1856) The moral and intellectual diversity of races. Filadelfia: Lippincott.

De Graef, K., (1999a) "Les étrangers dans les textes paléobabyloniens tadifs de Sippar" (première partie), Akkadica $111: 1-48$.

De Graef, K., (1999b) "Les étrangers dans les textes paléobabyloniens tadifs de Sippar” (deuxième partie), Akkadica 112: 1-17

Devalle, S. (1999) "Etnicidad e identidad: usos, deformaciones y realidades", Estudios de Asia y África 34(1): 33-50.

Di Bennardis, C. (2006) Construcción de identidades étnicas, cultura y poder político en la Mesopotamia del III milenio a.C., Tesis de Doctorado, Facultad de Humanidades y Artes, UNR, 2006 (inédita) 
La problemática etno-identitaria en sociedades escribales extinguidas: Mesopotamia en el III milenio a.C. Cuestiones historiográficas y metodológicas

Di Bennardis, C. \& Silva Castillo, J. (2005) "Diversidad étnica, integración o victimización en la Mesopotamia del III milenio a.C.”. En Di Bennardis, C. \& Silva Castillo, J. El Cercano Oriente antiguo: nuevas miradas sobre viejos problemas, Rosario: UNR-El Colegio de México, pp.11-27.

Di Bennardis, C. \& Silva Castillo, J. (2011) ¿"Centros urbanos-periferia pastoril? Procesos de agregación y desagregación de la etnia amorrea en el contexto socioespacial diverso del Reino de Mari (siglo XVIII a.C.)". En Di Bennardis, C., D`Agostino, F., Silva Castillo, J., Milevski, I. (eds.) Relaciones centro-urbano periferia en la Mesopotamia y zonas contiguas del Cercano Oriente. Actas del Taller realizado en la Universidad Nacional de Rosario, Argentina. 21-23 de Mayo de 2009, Rivista degli Studi Orientali, (RSO) Nova Serie, 83 (1- 4). Roma: Fabricio Serra Editori, pp. 79-114

Di Bennardis, C.; Koldorf, A. E.; Rovira, L. \& Luciani, F. (comps) (2013) Experiencias de la Diversidad. UNR Editora.

Diakonoff, I \& Starostin, S. (1986) Hurro-Urartian as an Eastern Caucasian Language. Múnich: Bücher aus dem Verlag R. Kitzinger.

Diakonoff, I. (1975) "The Rural Community in the Ancient Near East", Journal of the Economic and Social History of the Orient 18(2): 121-133.

Diakonoff, I. (1982) "The structure of Near Eastern society before the middle of the 2nd millennium B.C.", Oikumene 3:7-100.

Díaz-Polanco, H., (2000) "El conflicto cultural en el umbral del tercer milenio", Memoria 131: 34-43.

Durand, J.-M. (1992) "Unité et diversités au Proche-Orient à l'époque amorrite", En Charpin, D. y Joannes, F. La circulation des biens, des personnes et des idées dans le Proche-Orient ancien. Actes de la XXXVIIIe Rencontre Assyriologique Internationales, Paris, 1991. Paris: Editions Recherche sur les Civilisations, pp. 97-129.

Easton, D., (1959) "Political Anthropology", Biennial Review of Anthropology 1: 210-262.

Emberling, G. (2002) Ethnicity and the State in Early Third Millennium Mesopotamia. Dissertation of master Thesis. Ann Arbor: University of Michigan.

Emberling, G. (Ed.) (2016) Social Theory in Archaeology and Ancient History. Cambridge: University Press. 


\section{CRISTINA DI BENNARDIS}

Engelstadt, E. (1991) "Images of Power and Contradiction: Feminist Theory and Postprocessual Archaeology”, Antiquity 65: 502-514.

Field, H. (1933) "The Antiquity of Man in Southwestern Asia", American Antiquity 35: 51-62.

Foucault, M. (1992) Genealogía del Racismo. De la guerra de razas al racismo de Estado. Madrid: La Piqueta.

Fraser, N. (1998) "La justicia social en la era de las 'politicas de identidad': redistribución, reconocimiento y participación". Apuntes de investigación del CECYP 2: 17-36.

Fraser, N. (2000) “¿De la redistribución al reconocimiento? Dilema de las justicias en la era "postsocialista", New Left Review 0: 126-155.

Gasche, H., Armstrong, J.A., Cole, S.W. \& Gurzadyan, V.G. (1998) Dating the Fall of Babylon. A Reappraisal of Second Millenium Chronology. Chicago-Gantes: The Oriental Institute-The University of Ghent.

Gelb, I (1960) "Sumerians and Akkadians in their Ethno-linguistic Relations", Genava, 8: 258-271.

Gelb, Ignace (1944) Hurrians and Subarians. Chicago: The University of Chicago Press.

Gellner, E. (1990 [1ra. ed. inglés 1986]) La lógica de la escritura y la organización de la sociedad. Madrid: Alianza.

Gellner, E. (1991 [1ra. ed. inglés 1983]) Naciones y nacionalismo. Buenos Aires: Alianza Universidad.

Gellner, E., (1993 [1ra. ed. inglés 1987]) Cultura, identidad y política. Barcelona: Gedisa.

Godelier, M. (1976) "Presentación”, En Polanyi, K. et ali. (1976 [1ra. ed. inglés 1956]) Comercio y mercado en los Imperios Antiguos. Barcelona: Labor universitaria, pp.9-37.

Goffman. E., 1989 (lra. ed. inglés 1963) Estigma. La identidad deteriorada. Buenos Aires: Amorrortu.

González Alcantud, J. (1998) Antropología (y) politica. Sobre la formación cultural del poder. Barcelona: Anthropos. 
La problemática etno-identitaria en sociedades escribales extinguidas: Mesopotamia en el III milenio a.C. Cuestiones historiográficas y metodológicas

Goody, J. (1985 [1ra. ed. inglés 1977]) La domesticación del pensamiento salvaje. Madrid: Akal.

Goody, J. (1990 [1ra. ed. inglés 1986]) La lógica de la escritura y la organización de la sociedad. Madrid: Alianza.

Hallo, W., (1987) "Sumerian Historiography", en Tadmor, H. \& Weinfeld, M. History, Historiography and Interpretation. Studies in Biblical and Cuneiform Literatures. Leiden: Brill.

Harris, M. (1979 [1ra. ed. inglés 1968]) El desarrollo de la teoría antropológica. Madrid: Siglo XXI.

Helm, J. (Ed.) (1968) Essays on the Problem of Tribe. Proceedings of the 1967 Annual Spring Meeting of the American Ethnology Society. Seattle: University of Michigan Press.

Hidalgo, C. \& Tamagno, L. (1992) Etnicidad e Identidad. Buenos Aires: CEAL.

Hobsbawm, H. \& Ranger, R. (Ed.) (1983) The Invention of Tradition. Cambridge: Cambridge Univesity Press.

Hobsbawm, H. (1993/94) "Nación, estado, etnicidad y religión: transformaciones de la identidad", Anuario de la Escuela de Historia 16. UNR: 9-19.

Hooder, I., (1988 [1ra. ed. inglés 1986]) Interpretaciones en Arqueología. Barcelona: Crítica.

Huntington, S. (1997) El choque de civilizaciones y la reconfiguración del orden mundial. Buenos Aires: Paidós.

Hurbon, L. (1993 [1ra. ed. francés 1987]) El bárbaro imaginario. México: FCE.

Jacobsen, T. (1939) "The Assumed Conflict Between Sumerians and Semites in Early Mesopotamian History" Journal of the American oriental society 59 (4): 485-495.

Jacobsen, T. (1978-1979) "Iphur-Kishi and His Time", Archiv für Orientforschung 26: $1-14$.

Jacobson-Widding, A. (1983) Identity: Personal and Socio-Cultural. Upsala: Academiae Upsaliensis. 


\section{CRISTINA DI BENNARDIS}

Jason, H. (1977) Ethnopoetry: Form, Content, Function. Bonn: Linguistica Biblica.

Jason, H. (1979) "The poor man of Nippur: an ethnopoetic analysis", Journal of Cuneiform Studies 31(4): 189-215.

Jason, H., (1969) "A multidimensional approach to oral literature", Current Anthropology 10 (4): 413-426.

Kamp, K. \& Yoffee, N. (1980) "Ethnicity in Ancient Western Asia During the Early Second Millennium B.C.: Archaeological Assessments and Ethnoarchaeological Prospectives", Bulletin of the American Schools of Oriental Research 237: 85-104.

Knapp, B. (1987) Archaeology, Annales, and ethnohistory. Cambridge: Cambridge University press.

Kramer, S. N. (1990) “The Marriage of Martu”, En Klein, J. \& Skaist, A. (eds.) Bar-Ilan Studies in Assyriology Dedicated to Pinhas Artzi. Ramat: Bar-Ilan University Press, pp. 11-27.

Kramer, S.N. (1963) The Sumerians, Their History, Culture and Character. Chicago:The University of Chicago Press.

Lafont, S., (1998) "Le Roi, le Juge et 1'Étranger a Mari et dans La Bible", Revue d'Assyriologie et d'archéologie orientale 92: 161-181.

Landsberger, B. (1944) "Die Anfänge der Zivilisation in Mesopotamien”, Dil Tarih ve Cografya Fakültesi Dergisi 2: 431-437

Langdon, S. (1924) Excavations at Kish I (1923-1924). Paris: Geuthner

Leach, E. (1977 [1era ed. inglés 1954]) Sistemas politicos de la Alta Birmania. Barcelona: Anagrama.

Leone, M. \& Shackel, P. (1987) “Toward a Critical Archaeology", Current Anthropology 28 (3): 251-282.

Levi-Strauss, C. (Dir.) (1981 [1era ed. francés 1977]) Seminario. La identidad. Barcelona: Petrel.

Lewellen, T. (1985 [1ra. ed. inglés 1983]) Antropología Política. Barcelona: Bellaterra. 
La problemática etno-identitaria en sociedades escribales extinguidas: Mesopotamia en el III milenio a.C. Cuestiones historiográficas y metodológicas

Liverani, M. (1983) "Political lexicon and political ideologies in the Amarna Letters", Berytus. Archaeological Studies 33: 41-56.

Liverani, M. (1995 [1ra. ed. italiano 1989]) El Antiguo Oriente. Historia, sociedad y economía. Barcelona: Crítica.

Luke, J.T. (1965) Pastoralism and Politics in the Mari Period, Ph.D. dissertation. Ann Arbor: University of Michigan.

Malamat, A. (1967) "Aspect of tribal societies in Mari and Israel”. En Kupper, J. R. La civilisation de Mari. XVe Rencontre Assyriologique Internationale. París: Les Belles Letres, pp. 129-138.

Mander, P. \& Pomponio, F. (2002) "A Minor Old Babylonian Archive about the Transfer of Personnel”, Journal of Cuneiform Studies 53: 35-59

Mc Inerney, J. (ed.) (2014) A companion to Ethnicity in the Ancient Mediterranean. Chichester: Wiley Blackwell.

Meyer, E. (1906) Sumerier und Semiten in Babylonien. Berlin:Verlag Ven Konigl

Michalowski, P. (1984) "History as Charter: Some observations on the Sumerian King List", En Sasson, J., Studies in Literature From the Ancient Near East: Dedicated to Samuel Noah Kramer. New Haven: American Oriental Society, pp. 237-248

Moortgat, A. (1969) The Art of Ancient Mesopotamia. Londres: Phaidon.

Morgan, L. (1971 [1era. ed. en inglés 1877]) La sociedad primitiva. Madrid: Universidad Complutense de Madrid.

Moscati, S. (1959) The Semites in Ancient History. Cardiff: University of Wales Press.

Nagel, J. (1989) "La persistencia de la etnicidad. Aspectos nacionales e internacionales de los movimeintos étnicos modernos". En Pérez-Agote, A. (Ed.) Sociología del Nacionalismo. Bilbao: Servicio Editorial Universidad del País Vasco, pp. 77-93.

Nissen, H. (1988) The Early History of the Ancient Near East. 9000-2000 B.C.. Chicago: The University of Chicago Press.

Oppenheim, L. (1964) Ancient Mesopotamia. Portrait of a Dead Civilization. Chicago: The University of Chicago Press.

\section{anuario.}




\section{CRISTINA DI BENNARDIS}

Owusu, M., (1989) "La etnografía de los etnógrafos y la etnografía. Teoría y práctica de la antropologia sociocultural: una reconstrucción", Anuario de Etnología y Antropología Social 2: 109-134.

Pérez-Agote, A. (Ed.) (1989) Sociología del Nacionalismo. Bilbao: Servicio Editorial Universidad del País Vasco

Peters, J. (1919) "The home of the Semites", Journal of the American Oriental Society 39: 243-260.

Polanyi, K. et ali. (1976 [1ra. ed. inglés 1956]) Comercio y mercado en los Imperios Antiguos. Barcelona: Labor universitaria.

Porter, A. (2012) Mobile Pastoralism and the formation of Near Eastern Civilizations. Cambridge: Cambridge University Press.

Pritchard, J. (1969) The Ancient Near Eastern Tetxs relating to the Old Testament. Nueva Jersey: Princeton University Press.

Pujadas, J. J. (1993) Etnicidad. Identidad cultural de los pueblos. Madrid: Universidad Autónoma de Madrid.

Renfrew, C. \& Bahn, P. (2000 [1era ed. inglés]) Arqueología. Teorías, métodos y práctica. Londres: Thames and Hudson.

Renfrew, C. (1990 [1era ed. inglés 1987]) Arqueologia y lenguaje. Madrid: Crítica

Reynoso, C. (1998) Corrientes en antropología contemporánea. Buenos Aires: Biblos.

Rodríguez, G. 1988 "Identidad y autoconciencia, en una situación de contacto interétnico". Cuadernos de Antropología 2:21-38.

Rothman, M.S, (2015) "Early Bronze Age migrants and ethnicity in the Middle Eastern mountain zone", Proceedings of the National Academy of Sciences 112 (30): 9190-9195.

Ruiz Olabuénaga, J.I. (1989) "Reproducción étnica en el País Vasco: Dinámica y proceso”, En Pérez-Agote, A. (Ed.) Sociología del Nacionalismo. Bilbao: Servicio Editorial Universidad del País Vasco, pp.131-139.

Saggs, H.W.F. (2000) The people of the past Babylonians. Berkeley: University of California Press.

Said, E. (1990 [1ra. ed. inglés 1978]) Orientalismo. Madrid: Libertarias. 
La problemática etno-identitaria en sociedades escribales extinguidas: Mesopotamia en el III milenio a.C. Cuestiones historiográficas y metodológicas

Speiser, E. A. (1932) "The Bearing of the Excavations at Tell Billa and Tepe Gawra upon the Ethnic Problems of Ancient Mesopotamia", American Journal of Archaeology 36 (1): 29-35.

Speiser, E. A., (1950-1951) "The Sumerian Problem Reviewed", Hebrew Union College Annual 23 (1): 1950-51.

Sprigg, M. (1984) Marxist Perspectives in Archaeology. Cambridge: Cambridge University Press.

Tamagno, L. (1988). "La construcción social de la identidad étnica". Cuadernos de Antropología 2: 48-59.

Taylor, C. (1999 [1era ed. en Ingles 1992]) El multiculturalismo y la politica de reconocimiento. México: FCE.

The Electronic Text Corpus of Sumerian Literature http:// https://etcsl.orinst.ox.ac.uk/ creado por la Universidad de Oxford en 1997.

Thomsen, M.L. (1984) The Sumerian Language: An Introduction to its History and Grammatical Structure. Copenhague: Akademisk Forlag.

Trinchero, H.H., (2000) Los dominios del demonio. Civilización y barbarie en las fronteras de la Nación. El Chaco Central. Buenos Aires: Eudeba.

Turner, V. (1967) The forest of symbol: Aspects of ndembu ritual. Ithaca: Cornell University Press.

Tylor, E.B. (1977 [1era ed. en inglés 1871]) La cultura primitiva. Madrid: Ayuso.

Unnag, A. (1936) Subartu. Beitrage zur Kulturgeschichte und Volkerkunde Vorderasiens. Berlin: De Gruyter.

Verderame, L., (2013) “¿Un pueblo imaginario?: la creación de la identidad amorrea en los estudios asiriológicos", En Di Bennardis, C., Milevski, I., Ravenna, E. (Eds.), Diversidad de formaciones politicas en Mesopotamia y el Cercano Oriente. Organización interna y relaciones interregionales en la Edad del Bronce. Barcelona: Barcino - Universidad Autónoma de Barcelona, pp. 41-55.

Von Soden, W. (1937) Der Aufstieg des Assyrerreiches als geschichtliches Problem. Leipzig: J.C. Hinrichs.

VV.AA., (1960) Le racisme devant la science. París: Unesco-Gallimard. 


\section{CRISTINA DI BENNARDIS}

White, H. (1985) Tropics of discourse. Essays in Cultural Criticism. BaltimoreLondres: The John Hopkins University Press. 